\title{
(MAL)ADAPTIVE COGNITIONS AS PREDICTORS OF STATISTICS
} ANXIETY

\author{
SARA-EMILIE McINTEE \\ University of Ottawa \\ smcin009@uottawa.ca \\ JEAN-CHRISTOPHE GOULET-PELLETIER \\ University of Ottawa \\ jgoul014@uottawa.ca \\ ALEXANDRE WILLIOT \\ University of Quebec in Chicoutimi \\ alexandre_williot@uqac.ca \\ EMMA DECK-LÉGER \\ University of Ottawa \\ emmadleger@gmail.com \\ DANIEL LALANDE \\ University of Quebec in Chicoutimi \\ daniel.lalande@uqac.ca \\ MICHAEL CANTINOTTI \\ University of Quebec in Trois-Rivières \\ michael.cantinotti@uqtr.ca \\ DENIS COUSINEAU \\ University of Ottawa \\ denis.cousineau@uottawa.ca
}

\begin{abstract}
A vast majority of social sciences students experience statistics anxiety in their statistics class, a course often perceived as the most difficult one of their academic paths. The present study examines the role of attitudes towards statistics, cognitive emotion regulation strategies, and satisfaction of psychological needs in the prediction of statistics anxiety as well as the contribution of gender onto statistics anxiety. Two hundred forty-two undergraduate social sciences students in Canada completed the study. Positive attitude towards statistics, fewer maladaptive emotion regulation strategies, and satisfaction of psychological needs were related to less statistics anxiety; adaptive emotion regulation strategies, however, were not. Furthermore, women experienced more statistics anxiety than men. Results provide insight about individual differences that may impact experiences of statistics anxiety and overall learning in the context of a statistics course.
\end{abstract}

Keywords: Statistics education research; Statistics anxiety; Teaching of statistics; Emotion regulation strategies; Psychological needs; Attitudes

Statistics Education Research Journal, 21(1), Article 5. https://doi.org/10.52041/serj.v21i1.364

(C) International Association for Statistical Education (IASE/ISI), February 2022 


\section{INTRODUCTION}

Social sciences promote the advancement of scientific knowledge through empirical investigation. For this reason, students in social sciences disciplines are required to develop skills in statistical analysis and data interpretation. Learning statistics, however, is very different from learning course material taught in other social sciences subjects. Because mathematical formalism is sometimes used to convey statistical concepts, learning statistics has been compared to learning new content taught using a foreign language (Lalonde \& Gardner, 1993; Lazar, 1990; Onwuegbuzie, 2003). It is therefore not surprising that a majority of social sciences students experience statistics anxiety (Field, 2010). Although most studies on statistics anxiety were done with English-speaking students, this phenomenon also affects German-speaking students (Macher et al., 2015), Spanish-speaking students (Vigil-Colet et al., 2008) and French-speaking students (Cantinotti et al., 2017).

Statistics anxiety is broadly defined as "the feelings of anxiety encountered when taking a statistics course or doing statistical analyses" (Cruise et al., 1985, p. 92) and was conceptualized as being a specific type of academic anxiety that, although closely related to, is distinguishable from test anxiety and mathematics anxiety (Benson, 1987, 1989). One of the earliest definitions of statistics anxiety was given by Zeidner (1991) who defined the concept as a:

... performance anxiety characterized by extensive worry, intrusive thoughts, mental disorganization, tension, and physiological arousal. Statistics anxiety arises in people when exposed to statistics content, problems, instructional situations, or evaluative contexts, and is commonly claimed to debilitate performance in a wide variety of academic situations by interfering with the manipulation of statistics data and solution of statistics problems. (p. 319)

Later, Dettmers et al. (2011) proposed a more concise definition where statistics anxiety is described as negatively anticipating a statistics course and experiencing unpleasant emotions while taking the course. More recently, Chew and Dillon (2014) redefined statistics anxiety to include its negative effects and its relationship with mathematics anxiety and attitudes towards statistics:

... a negative state of emotional arousal; experienced by individuals as a result of encountering statistics in any form and at any level; this emotional state is preceded by negative attitudes toward statistics and is related to but distinct from mathematics anxiety. (p. 199)

Herein, we adopted the conceptualization of Vigil-Colet et al. (2008) for which statistics anxiety has three components: anxiety of asking for help, anxiety of evaluation, and anxiety of interpretation. The first probably has its root in social performance whereas the second probably has links with trait anxiety (Macher et al., 2015).

Statistics anxiety was found to be an important negative predictor of academic performance (i.e., final course grade obtained in a statistics course; see Macher et al., 2015; $n=147$ ), explaining a little over $10 \%$ of the variance in grades. Cantinotti et al. (2017) found a similar effect in French speaking undergraduate students in psychology $(n=268)$. Another study also reported that the desire to avoid a bad grade in a statistics course (i.e., performance avoidance goals) increased statistics anxiety, the desire to get a good grade (performance approach goals) had a neutral effect on anxiety and finally the desire to master statistics decreased it (Lalande et al., 2019). Similarly, to a desire to master course content, a lower level of anxiety has also been linked to a positive attitude towards statistics (e. g., Chiesi \& Primi, 2010; Garnefski et al., 2001; Mji \& Onwuegbuzie, 2004; Onwuegbuzie, 2000; Watson et al., 2003; Watson et al., 2002) and a better academic performance (Roberts \& Bilderback, 1980; Roberts \& Saxe, 1982; Slootmaeckers et al., 2014).

Herein, we examine two new factors: cognitive emotion regulation strategies (Garnefski et al., 2001) and the satisfaction of basic psychological needs (Ryan \& Deci, 2017). The impact of these two factors on statistics anxiety is still undocumented and may help find new approaches to reduce statistics anxiety. 


\section{BACKGROUND}

We review three factors known to influence anxiety in other domains, although two were not examined specifically in the context of statistics anxiety.

\subsection{TWO POTENTIALLY PROTECTIVE FACTORS AGAINST STATISTICS ANXIETY: ATTITUDES TOWARDS STATISTICS AND SATISFACTION OF PSYCHOLOGICAL NEEDS}

One variable that has repeatedly been associated with lower levels of statistics anxiety is holding a positive attitude towards the subject (e. g., Ncube \& Moroke, 2015; O’Bryant, 2017). According to Schau (2003a), attitudes towards statistics refer to one's tendency to like or dislike learning statistics. Most definitions are inconsistent; however (see Chew \& Dillon, 2014, for a review), some authors defining the construct of attitude as strictly affective (Evans, 2007; Gal \& Ginsburg, 1994; Mills, 2004; Rhoads \& Hubele, 2000; Roberts \& Bilderback, 1980), with others defining it as multidimensional and being comprised of cognitive, affective, and behavioral components (Chiesi \& Primi, 2009; Olson \& Zanna, 1993). One concrete example of the ambiguity of the definition is found in one of the earliest statistics anxiety rating scales (STARS; Cruise et al., 1985), which has been criticized as reporting both measures of statistics anxiety (interpretation anxiety, test and class anxiety, fear of asking for help) and measures of attitudes towards statistics (worth of statistics, computation self-concept, and fear of statistics teacher; Chew \& Dillon, 2014; Macher et al., 2013; Papousek et al., 2012). In the mid-1990's, Schau and colleagues (1995) proposed a first version of the Survey of Attitudes Toward Statistics (SATS-28), which was later revised to include 36 items (SATS-36; Schau, 2003b). This tool was designed to study attitudes towards statistics as a multidimensional construct consisting of six dimensions: affect, cognitive competence, value, difficulty, interest, and effort.

As previously discussed, more positive attitudes towards statistics have been associated with lower statistics anxiety and greater course performance (e. g., Chiesi \& Primi, 2010). One study (Najmi et al., 2018) suggested a model where positive attitudes towards statistics decrease the negative effects of statistics anxiety, which positively impact academic performance $(n=320)$. Researchers have also reported benefits for individual components of attitudes. For instance, Slootmaeckers and colleagues (2014) found that perceived easiness of course content was beneficial to long-term retention of statistical skills $(n=157)$. Moreover, an interest in statistics was related to less statistics anxiety (Macher et al., 2012; Macher et al., 2013; Slootmaeckers et al., 2014).

Another variable that could play a protective role against statistics anxiety is the satisfaction of psychological needs. According to Self-determination Theory (Deci \& Ryan, 1980, 1991, 1995; Ryan \& Deci, 2017), individuals' basic psychological needs (i.e., competence, autonomy, and relatedness) must be satisfied to achieve optimal development and functioning (Deci \& Ryan, 2000b, Ryan \& Deci, 2017). Deci et al. (1991) defined competence as the experience of self-efficacy in the attainment of various outcomes, relatedness as the development of secure and satisfying connections with other individuals, and autonomy as one's ability to self-initiate and self-regulate one's actions. Competence, relatedness, and autonomythe three psychological needs - were since found to be negatively related to general anxiety (Bartholomew et al., 2011; Deci \& Ryan, 2000b; Quested et al., 2011; Wei et al., 2005). No prior research, however, has examined satisfaction of psychological needs in relation to statistics anxiety specifically. Moreover, past research has shown that individuals with satisfied psychological needs reacted less negatively to external stressors (Hodgins et al., 2006; Hodgins et al., 2010; Parker et al., 2013), suggesting that satisfied psychological needs may be related to fewer maladaptive and more adaptive cognitive emotion regulation strategies, as discussed next. This second path whereby psychological needs may influence statistics anxiety (through regulation strategies) suggests that interaction effects are a possibility. We therefore considered the moderation effects of satisfactions of psychological needs in what follows. 


\subsection{A POTENTIAL RISK FACTOR FOR ANXIETY: POOR EMOTION REGULATION STRATEGIES}

Statistics anxiety is not unlike other types of anxiety (Andrews \& Wilding, 2004; Kassel et al., 2007) for which adequate emotion regulation processes allow the system to return to a calmer state (Cruise et al., 1985; Onwuegbuzie et al., 1997; Zeidner, 1991). In the context of a statistics course, anxiety could be reflective of poor emotion regulation related to past failures in a similar context (e. g., mathematics course). From this viewpoint, statistics anxiety would not simply be a result of the statistics course but also an indicator of pre-existing maladaptive emotion regulation strategies.

Emotion regulation can be defined as a wide range of strategies used to reduce, maintain, or increase an emotion (e.g., social, cognitive, behavioral; Gross, 2001). Cognitive emotion regulation refers to the cognitive processes involved in the assessment and management of emotionally arousing information (Gross, 2001; Thompson, 1991).

In 2001, Garnefski et al. proposed nine cognitive strategies of emotion regulation, which can be categorized as either adaptive (i.e., acceptance, refocus on planning, positive refocusing, positive reappraisal, and putting into perspective) or maladaptive (i.e., self-blame, blaming others, rumination, and catastrophizing). Studies have since found that self-blame, rumination, and catastrophizing were related to greater anxiety (Garnefski \& Kraaij, 2007; Omran, 2011; $n=611$ and 484, respectively), while refocus on planning, positive refocusing, and positive reappraisal were related with lower levels of anxiety (Omran, 2011). Similarly, to findings on generalized anxiety, it is plausible that maladaptive strategies aggravate, while adaptive strategies improve, symptoms of statistics anxiety. To our knowledge, no study has examined the cognitive emotion regulation strategies in the context of statistics anxiety specifically.

\subsection{AIM OF THE STUDY}

The purpose of this study is to examine the relationship between cognitive emotion regulation strategies (maladaptive and adaptive) and attitude towards statistics. Satisfaction of psychological needs on statistics anxiety was included to see if it modulates the previous three factors influencing statistics anxiety. We hypothesize that (1) maladaptive cognitive emotion regulation strategies will be positively related to statistics anxiety; (2) adaptive cognitive emotion regulation strategies will be negatively related to statistics anxiety; and (3) satisfaction of psychological needs will moderate the relation between cognitive emotion regulation strategies (maladaptive and adaptive) and statistics anxiety as well as the relation between attitudes towards statistics and statistics anxiety. Finally, as gender is strongly associated to statistics anxiety in all the published research, we also include this variable in the present study. We expect to find a greater statistics anxiety in women than in men and will investigate the link between gender and the predictors examined.

\section{METHOD}

In this study, we examine four possible predictors of statistics anxiety, specifically, attitudes towards statistics, cognitive emotion regulation strategies (both maladaptive and adaptive), and satisfaction of psychological needs. We also include gender as a covariate of these four predictors and the dependent variable, statistics anxiety.

\subsection{PARTICIPANTS}

We recruited 270 social sciences undergraduate students from six classes located in five French speaking universities in Canada in the winter semester of 2017. Their distribution by university is shown in Table 1. Additional participant characteristics are reported in the results section. 


\subsection{PROCEDURE}

Data were collected in the classroom, on average during the tenth week of class. Participants were approached during their statistics course by one of the experimenters and invited to complete the survey using paper and pencil. In order to avoid students feeling compelled to participate in the research, the instructor was absent from the classroom for the duration of the procedure. The questionnaires took 20 to 25 minutes to answer. Participants were given a chance to win one of six gift cards of a value of CAN\$50.

\subsection{MEASURES}

The whole study comprised sociodemographic questions and four French-validated questionnaires, with 117 items in total. Measures are described below.

Sociodemographic and contextual information. Data collection started with sociodemographic and contextual items: respondent's gender (Man, Woman, Other / do not want to answer coded as 0, 1, and 2, respectively), age, program of study, number of years of schooling completed, class size as perceived by the student, and number of weeks since the beginning of the course.

Statistics anxiety. Statistics anxiety was measured using the Statistics Anxiety Scale (SAS; Vigil-Colet et al., 2008). This measure consists of 24 items forming three 8-item subscales: evaluation anxiety, asking for help anxiety, and interpretation anxiety. The present study uses the French version for which validation evidence was provided by Cantinotti et al. (SAS-F; 2017) who found a Cronbach's alpha of 0.93 for the overall scale. This scale has three subscales: (i) Anxiety of asking for help (e.g., Going to ask my statistics teacher for individual help with material I am having difficulty understanding) with a Cronbach's alpha of 0.92 in the original study; (ii) Anxiety of evaluation (e.g., Studying for an examination in a statistics course) with an alpha of 0.874; and (iii) anxiety of interpretation (e.g., Interpreting the meaning of a table in a journal article) with an alpha of 0.819 . For each item, participants indicated their level of agreement on a scale ranging from 1 ("no anxiety") to 5 ("considerable anxiety") for a score falling within the range of 8 to 40 on each subscale and a total possible score between 24 and 120. A higher score implied more statistics anxiety.

Attitudes towards statistics. Attitudes towards statistics was measured using the Survey of Attitudes toward Statistics (SATS-36; Schau, 2003b). This measure consists of 36 items grouped into six subscales: affect (the appreciation of statistics, e. g., I will like statistics), cognitive competence (a self-assessment of intellectual competence and ability to apply statistics, e. g., I will have trouble understanding statistics because of how I think), value (the perception of the necessity of statistics in life, e. g., Statistics should be a required part of my professional training), the difficulty of the course (e. g., Statistics formulas are easy to understand), the level of interest in statistics (e. g., I am interested in using statistics), and the effort that the student is ready to devote to this statistics course (e. g., I plan to complete all of my statistics assignments). The present study uses the French version of the scale translated and with validity evidence provided by Carillo et al. in 2016 (note that the items were not numbered, and the two pages of the questionnaire were presented in the reverse order, i.e., item 19 was presented first). The scale had good internal consistency with a published Cronbach's alpha of .89. For each item, participants indicated their level of agreement on a scale ranging from 1 ("strongly disagree") to 7 ("strongly agree") for a total possible score between 36 and 252. Nineteen negatively formulated items were reverse coded. A higher score implies a more positive attitude towards statistics.

Cognitive emotion regulation strategies. Emotion regulation strategies were measured using the Cognitive Emotion Regulation Questionnaire (CERQ; Garnefski et al., 2001). This questionnaire consists of 36 items measuring nine cognitive strategies that can be categorized as adaptive (i.e., acceptance, refocus on planning, positive refocusing, positive reappraisal, and putting into perspective for a total of 20 items) 
or maladaptive (i.e., self-blame, blaming others, rumination, and catastrophizing, for a total of 16 items). An example of an adaptive item is I think I can learn something from the situation; an example of maladaptive item is I think that basically the cause must lie within myself.

The present study uses the French version proposed by Jermann and colleagues (2006) in which Cronbach's alphas were .82 and .89 for maladaptive and adaptive strategy subscales, respectively. For each item, participants answered on a five-point scale ranging from 1 ("almost never") to 5 ("almost always") for a score ranging from 20 to 100 on the adaptive subscale and from 16 to 80 on the maladaptive subscale. A high score on the adaptive subscale implies more adaptive cognitive regulation strategies and a high score on the maladaptive subscale implies more maladaptive cognitive emotion regulation strategies.

Satisfaction of psychological needs. Satisfaction of psychological needs was measured using the Basic Psychological Need Satisfaction Scale - General (Deci \& Ryan, 2000a). This measure consists of 21 items grouped into three subscales that represent psychological needs: competence (e. g., People I know tell me I am good at what I do), autonomy (e. g., I feel like I am free to decide for myself how to live my life), and relatedness (e. g., I really like the people I interact with). The present study uses the French translated questionnaire proposed by Shankland (2014; internal consistency was not available in the French translation but was good in its original version with Cronbach's alpha of 0.84). For each item, participants indicated their level of agreement on a scale ranging from 1 ("not at all true") to 7 ("very true"), for a total score falling within the range of 21 to 147. Nine negatively formulated items were reverse coded. A higher score implies more satisfaction of psychological needs.

Measurement error is assumed non-systematic; thus, all scale statistics are presented with a single decimal and the standardized statistics with two (Cousineau, 2020).

\subsection{DATA SCREENING}

Participants' response rate was high $(80 \%-90 \%)$ for all universities except for the University of Montreal (30\%). Table 1 lists participant response rates at individual universities. It was found after the fact that participants from Laval University were enrolled at the graduate studies level; since the present study aims to examine statistics anxiety at the undergraduate level only, the thirty participants from this university were excluded from all subsequent analyses.

Table 1. Participation rate of students by university $(N=270)$

\begin{tabular}{lccc}
\hline University & Enrolled students & Participants & $\%$ participation \\
\hline University of Ottawa & 25 & 22 & $88 \%$ \\
University of Quebec in Trois- & 69 & 56 & $81 \%$ \\
Rivières (Class 1) & 56 & 45 & $80 \%$ \\
University of Quebec in Trois- & 205 & 62 & $30 \%$ \\
Rivières (Class 2) & 71 & 58 & $82 \%$ \\
University of Montreal & 30 & 27 & $90 \%$ \\
University of Quebec in Chicoutimi & & & \\
Laval University & & & \\
\hline
\end{tabular}

Missing values examinations revealed that only one participant (out of the remaining 243) was missing responses to more than nine items: a participant from University of Montreal was missing 76 responses out of 117 items. This subject was excluded from the following analyses. The final sample comprised of 242 participants. Two participants chose not to answer the gender item, and two more selected "Other/do not want to answer" response. Because two participants are too few for estimation, these participants' gender were recoded as missing. Finally, deviation from normality was assessed with Fisher skewness. All total 
scales had mild deviations from normality. The three subscales of statistics anxiety, however, had notable skew in either direction (explaining that the total skew was close to zero). Skewness indices along with 95\% confidence intervals are given in Table 2. The Cronbach alphas indicating the reliability of the questionnaires are also shown in Table 2. All alpha equaled or exceeded the originally published alphas, indicating that the questionnaires operated as expected.

To facilitate interpretation of the results, we transformed scores so that total scores on each scale would fall within the range of 0 to 100 . To do so, we subtracted the minimum possible score on a scale (e.g., minimum score for statistics anxiety is 24) from participants' total score on that scale, then divided by the range of possible scores (difference between the maximum possible score and the minimum possible score). Finally, the quotient was multiplied by 100 . Thus, a total score of 72 out of 120 on statistics anxiety became a score of 50 out of 100 .

$$
\frac{72-24}{120-24} * 100=50
$$

This procedure was used for all scale scores (i.e., statistics anxiety, attitudes towards statistics, adaptive emotion regulation strategies, maladaptive emotion regulation strategies, and satisfaction of psychological needs). 
Table 2. Descriptive statistics of study's main variables $(N=242$, apart from gender where $N=238)$.

\begin{tabular}{|c|c|c|c|c|c|c|}
\hline Scale & $M$ & $S D$ & Min. & Max. & Skew & $\alpha$ \\
\hline Statistics anxiety (overall) & $46.1[43.9,48.4]$ & $17.8[16.3,19.5]$ & 1.0 & 93.8 & $+0.18[-0.13,+0.48]$ & $.93[.92, .95]$ \\
\hline Anxiety of asking for help & $35.2[31.5,38.9]$ & $29.0[26.6,31.8]$ & 0.00 & 100.0 & $+0.55[+0.24,+0.86]$ & $.98[.98, .98]$ \\
\hline Anxiety of evaluation & $75.5[72.8,78.1]$ & $20.9[19.2,23.0]$ & 3.1 & 100.0 & $-1.13[-1.44,-0.82]$ & $.91[.90, .93]$ \\
\hline Anxiety of interpretation & $27.6[25.2,30.1]$ & $19.6[18.0,21.5]$ & 0.0 & 93.8 & $+0.69[+0.38,+0.99]$ & $.87[.84, .89]$ \\
\hline Attitudes towards statistics & $58.7[56.8,60.6]$ & $15.1[13.9,16.6]$ & 14.3 & 89.9 & $-0.25[-0.55,+0.06]$ & $.92[.90, .93]$ \\
\hline $\begin{array}{l}\text { Maladaptive cognitive emotion } \\
\text { regulation }\end{array}$ & $36.5[34.8,38.1]$ & $12.9[11.9,14.2]$ & 7.8 & 84.4 & $-0.32[-0.62,-0.01]$ & $.82[.78, .85]$ \\
\hline $\begin{array}{l}\text { Adaptive cognitive emotion } \\
\text { regulation }\end{array}$ & $58.9[37.0,40.8]$ & $15.0[13.7,16.4]$ & 23.8 & 92.5 & $-0.23[-0.54,+0.08]$ & $.89[.86, .91]$ \\
\hline $\begin{array}{l}\text { Satisfaction of psychological } \\
\text { needs }\end{array}$ & $70.6[69.1,72.2]$ & $12.4[11.4,13.7]$ & 39.9 & 97.9 & $-0.13[-0.43,+0.18]$ & $.84[.81, .87]$ \\
\hline Gender & $n(\%)$ & & & & & \\
\hline Women & $195(82)$ & & & & & \\
\hline Men & $43(18)$ & & & & & \\
\hline
\end{tabular}

Note. Data in the table represent scores after transformation on a scale of 0 to 100 except for gender where men were coded 0 and women $1 . \alpha$ : Cronbach's alpha. Number between brackets represents the $95 \%$ confidence intervals of the statistic (see Harding et al., 2014, for a review). 


\subsection{DESCRIPTION OF THE SAMPLE}

Of the 242 participants, there were 195 women, 43 men, and four individuals who selected "other" or did not answer. This 5:1 ratio is representative of the student population in social sciences. Participants were 18 to 43-years-old $(M=21.85 ; S D=4.25$; the age of nine participants was unavailable). Two hundred and six participants studied in psychology, 27 studied in a joint program involving psychology (e.g., psychoeducation, psychosociology, psycholinguistics, etc.), six were in linguistics, two were independent students with no specific field of study, and one participant did not specify a program of study.

As seen in Table 2, students had on average a total score below 50 out of 100 on the statistics anxiety and the maladaptive cognitive emotion regulation strategies scales, and a score above 50 on the attitude towards statistics, adaptive cognitive emotion regulation strategies and satisfaction of psychological needs scales.

\section{RESULTS}

\subsection{CORRELATIONS}

Correlation results for scale totals are presented in Table 3. Consistent with our hypotheses, Pearson's correlations revealed that positive attitudes towards statistics $(r=-0.42, p<0.001)$, adaptive cognitive emotion regulation strategies $(r=-0.16, p=0.01)$, and satisfaction of psychological needs $(r=-0.34, p<$ $0.001)$ were negatively related to statistics anxiety, whereas maladaptive cognitive emotion regulation $(r=$ $0.34, \mathrm{p}<0.001)$ was positively related to statistics anxiety. Women were more likely than men to have a higher level of statistics anxiety $(r=+0.30, p<0.001)$, a more unfavorable attitude towards statistics $(r=$ $0.19, p=0.004)$, and fewer adaptive emotion regulation strategies $(r=-0.16, p=0.02)$.

Table 3. Pairwise correlations for all variables

\begin{tabular}{|c|c|c|c|c|c|c|}
\hline Variables & $N$ & 1 & 2 & 3 & 4 & 5 \\
\hline 1. Statistics Anxiety & 242 & 1 & & & & \\
\hline $\begin{array}{l}\text { 2. Attitudes towards } \\
\text { statistics }\end{array}$ & 242 & $\begin{array}{c}-.42 \\
{[-.51,-.30]}\end{array}$ & 1 & & & \\
\hline $\begin{array}{l}\text { 3. Maladaptive emotion } \\
\text { regulation strategies }\end{array}$ & 242 & $\begin{array}{c}+.34 \\
{[+.23,+.45]}\end{array}$ & $\begin{array}{c}-.07 \\
{[-.19,+.06]}\end{array}$ & 1 & & \\
\hline $\begin{array}{l}\text { 4. Adaptive emotion } \\
\text { regulation strategies }\end{array}$ & 242 & $\begin{array}{c}-.16 \\
{[-.28,-.04]}\end{array}$ & $\begin{array}{c}+.32 \\
{[+.21,+.43]}\end{array}$ & $\begin{array}{c}-.06 \\
{[-.18,+.07]}\end{array}$ & 1 & \\
\hline $\begin{array}{l}\text { 5. Satisfaction of } \\
\text { psychological needs }\end{array}$ & 242 & $\begin{array}{c}-.34 \\
{[-.45,-.22]}\end{array}$ & $\begin{array}{c}+.14 \\
{[+.02,+.26]}\end{array}$ & $\begin{array}{c}-.33 \\
{[-.44,-.21]}\end{array}$ & $\begin{array}{c}+.39 \\
{[+.28,+.49]}\end{array}$ & 1 \\
\hline 6. Gender & 238 & $\begin{array}{c}+.30 \\
{[+.18,+.42]}\end{array}$ & $\begin{array}{c}-.19 \\
{[-.31,-.06]}\end{array}$ & $\begin{array}{c}+.01 \\
{[-.13,+.14]}\end{array}$ & $\begin{array}{c}-.16 \\
{[-.28,-.03]}\end{array}$ & $\begin{array}{c}.01 \\
{[-.12,+.13]}\end{array}$ \\
\hline
\end{tabular}

Results showed that, consistent with the literature (e.g., Garnefski et al., 2001), maladaptive and adaptive emotion regulation strategies were weakly or not at all related. Results also showed that attitudes were weakly or not at all related to maladaptive regulation strategies $(r=-0.07, p=0.30)$, but moderately to strongly related to adaptive emotion regulation strategies $(r=+0.32, p<0.001)$.

\subsection{MULTIPLE REGRESSION ANALYSIS}

Gender covariate. Before performing a multiple linear regression, we estimated the intercept and the link between the gender covariable and all predictors. Table 4 shows the results. The covariate explained a negligible amount of variance of these four predictors (between $0 \%$ and $3.5 \%$ ). 
Gender was related to attitudes (Women: $M=57.49, S D=15.36$; Men: $M=64.85, S D=12.79$ ) women score six points lower than men on average on the measure of attitudes. Likewise, gender was associated with adaptive cognitive emotion strategies (Women: $M=57.92$, $S D=15.32$; Men: $M=64.04, S D=12.69$ ). Indeed, women students scored more than 5 points lower than men on average on this scale. Gender did not, however, appear to be related to total scores on measures of maladaptive emotion regulation strategies (Women: $M=36.47, S D=12.80$; Men: $M=36.11, S D=13.63$ ) and satisfaction of psychological needs (Women: $M=70.82, S D=12.48$; Men: $M=70.63, S D=12.52$ ).

Table 4. Summary of regression analyses of the covariate Gender for the four predictors $(N=238)$

\begin{tabular}{lcccccc}
\hline Predicted variable & Coefficient & Intercept & $\beta$ & $F(1,236)$ & \multicolumn{1}{c}{$p$} & $R^{2}$ \\
\hline Attitudes toward Statistics & $-7.4[-12.3,-2.4]$ & $64.9[60.4,69.3]$ & -0.187 & 8.54 & .004 & .035 \\
$\begin{array}{l}\text { Maladaptive emotion } \\
\text { regulation strategies }\end{array}$ & $0.36[-3.9,4.6]$ & $36.1[32.2,40.0]$ & 0.011 & 0.03 & .869 & .000 \\
$\begin{array}{l}\text { Adaptive emotion } \\
\text { regulation strategies }\end{array}$ & $-6.1[-11.1,-1.2]$ & $64.0[59.6,68.5]$ & -0.156 & 5.97 & .015 & .025 \\
$\begin{array}{l}\text { Basic satisfaction of } \\
\text { psychological needs }\end{array}$ & $0.2[-4.0,4.3]$ & $70.6[66.9,74.4]$ & 0.006 & 0.01 & .928 & .000 \\
$\begin{array}{l}\text { Note. Gender was coded } 0=\text { men, } 1=\text { women. } \beta \text { is the standardized coefficient. Numbers between brackets are } 95 \% \\
\text { confidence intervals. }\end{array}$
\end{tabular}

Multiple regression. A standard multiple linear regression was used to explore the relationship between the four predictors and gender and statistics anxiety. The results indicate that attitudes towards statistics $(b$ $=-0.40, t(231)=-6.1, p<0.001)$, maladaptive cognitive emotion regulation strategies $(b=0.34, t(231)=$ $4.5, p<0.001)$, and satisfaction of psychological needs $(b=-0.36, t(231)=-4.2, p<0.001)$ are related to statistics anxiety. Both attitudes and satisfaction of psychological needs were related to lower statistics anxiety, while maladaptive cognitive emotion regulation strategies were related to higher statistics anxiety. Adaptive cognitive emotion regulation strategies were weakly to moderately related to statistics anxiety $(b$ $=0.12, t(231)=1.7, p=0.09)$.

Among the studied variables, a positive attitude towards statistics was the most likely to be related to lower statistics anxiety ( 0.40 point of anxiety per point of attitude when both are expressed on 100 total score). A similar relationship was detected with respect to satisfaction of psychological needs $(-0.36)$. As seen in the previous subsection, both attitude and satisfaction of psychological needs were moderately correlated $(r=0.14, p<0.01)$. A positive relationship was detected for maladaptive cognitive emotion regulation strategies $(+0.34)$ but contrary to our hypothesis, a weak or negligible link between adaptive strategies and statistics anxiety was detected $(b=-0.12, t(231)=1.70, p=0.09)$. Note that the correlation between maladaptive and adaptive cognitive emotion regulation strategies was null, indicating that the two types of strategies are not simply flip sides of a same construct.

The regression analysis also estimated the link between gender and statistics anxiety. Results indicated that gender was, as expected, a strong indicator of statistics anxiety (women are predicted to score 13.9 points on average on 100 to statistics anxiety; $t(235)=4.94, p<0.001)$.

Altogether, the variables explained $37.5 \%$ of the variance in statistics anxiety $(F(5,232)=27.8, p<$ 0.001). Results of the multiple regression analysis are presented in Table 5. 
Table 5. Summary of multiple regression analysis for all predictors of statistics anxiety $(N=238)$

\begin{tabular}{lcccc}
\hline Predictor & Coefficient & $\beta$ & $t$ & $p$ \\
\hline Attitudes towards statistics & $-0.40[-.52,-.27]$ & -0.34 & -6.1 & .00 \\
Maladaptive emotion regulation strategies & $0.34[.19, .49]$ & 0.25 & 4.5 & .00 \\
Adaptive emotion regulation strategies & $0.12[-.02, .26]$ & 0.10 & 1.7 & .09 \\
Satisfaction of psychological needs & $-0.36[-.53,-.19]$ & -0.25 & -4.2 & .00 \\
Gender & $11.7[6.9,16.2]$ & 0.26 & 4.8 & .00 \\
Intercept & $65.2[49.4,81.0]$ & & 8.1 & .00 \\
\hline
\end{tabular}

Note. Gender was coded $0=$ men, $1=$ women. $\beta$ is the standardized coefficient. Numbers between brackets are $95 \%$ confidence intervals.

\subsection{MODERATION ANALYSIS}

We tested the moderation hypothesis that the satisfaction of psychological needs interacted with attitudes towards statistics and both, maladaptive and adaptive, cognitive emotions regulation strategies to predictor statistics anxiety, and included gender in our model as a covariate. Model fitting revealed that when satisfaction of psychological needs was entered as moderator, the interaction term with attitudes towards statistics $\left(\Delta R^{2}=0.003, F(1,229)=0.96, b=0.01, p=0.33\right)$, maladaptive $\left(\Delta R^{2}=0.000, F(1,229)\right.$ $=0.07, b=0.01, p=0.79)$, and adaptive cognitive emotion regulation strategies $\left(\Delta R^{2}=0.000, F(1,229)=\right.$ $0.18, b=0.00, p=0.68$ ) accounted for little of the proportion of the variance in statistics anxiety. The full model $R^{2}$ increased from 0.375 to 0.379 , whereas the root mean square error of prediction increased from 14.13 to 14.17 . Therefore, contrary to our hypothesis, satisfaction of psychological needs did not interact with the other factors to predict statistics anxiety.

We also explored moderation effects of satisfaction of psychological needs on the three subscales of statistics anxiety. The only significant result bears on an interaction of satisfaction of psychological needs with attitude on interpretation anxiety. Feeling competent, related, and autonomous may make students more open to see statistics with a positive attitude. The effect, however, is very small $\left(\Delta R^{2}=1.2 \% ; F(1\right.$, $229)=4.46, p=0.036)$. The interaction effect reduced interpretation anxiety by 0.01 points $[0.00,0.02]$ for each point of satisfaction of psychological needs $\times$ attitude towards statistics. For a participant one standard deviation away from the mean on these two predictors, this represents a decrease in statistics anxiety of only 2.2 points out of 100 .

Finally, as an attempt to identify new variables of interest, we explored the impact of perceived class size (i.e., perceived number of students in the course) on statistics anxiety. This variable had substantial variability across universities, with classes having as little as 20 students to classes having as many as 250 students. The size of the class indirectly reflects universities' policies and resources. We hypothesized that the students who perceived a smaller class size would find more support (for example, relatedness) in the classroom context and, therefore, experience lower levels of statistics anxiety. Surprisingly, exploratory analyses revealed only a weak link between perceived class size and statistics anxiety $(r=-0.09[-0.22$, $0.03], p=0.16)$. Furthermore, attitudes towards statistics were slightly more positive in larger classes $(r=$ $0.155[0.04,0.29], p=0.01)$. These results are difficult to interpret. To explain these findings, we propose tentatively that large classes could make anxious students feel more anonymous and therefore less targeted by the instructor's interactions. Overall, large class sizes could, by means of an avoidance strategy, be related to reduced levels of anxiety in the short-term. Although to be interpreted with caution, this explanation is coherent with perceived class size's small positive associations with maladaptive emotion regulation strategies (which includes avoidant strategies; $r=0.15$ [0.03, 0.28]. $p=0.02$ ), and the lack of satisfaction of one's psychological needs $(r=-0.22[-0.34,-0.10], p=0.001)$. Further work is required to disentangle the influence of class size on statistics anxiety, although we note that all effect sizes regarding class size were relatively small. Also note that one class (University of Montreal) had a much larger number 
of enrolled students and was also the class with the lowest participation rate (30\% whereas it was $80 \%$ and above in all other classes). It is possible that selection bias in that class influenced these results. Thus, they should be considered tentatively only.

\section{DISCUSSION}

The purpose of this study was to examine the relationship between attitudes towards statistics, cognitive emotion regulation strategies (maladaptive and adaptive), and satisfaction of psychological needs on statistics anxiety. Not surprisingly, students who reported more maladaptive cognitive emotion regulation strategies experienced more statistics anxiety than those with fewer maladaptive strategies. That said, adaptive cognitive emotion regulation strategies did not have a particularly strong relationship with statistics anxiety. Moreover, when three interaction terms were added in the regression model, results revealed negligible moderation effects. Therefore, contrary to our hypothesis, satisfaction of psychological needs did not moderate the relationship between attitudes and anxiety, or between emotion regulation and anxiety.

\subsection{WHEN EACH VARIABLE TELLS A DIFFERENT PART OF THE SAME STORY}

The main finding of the current study is that four different variables uniquely predicted statistics anxiety, altogether predicting $37.5 \%$ of the variance in statistics anxiety. More interesting, they were quite distinct predictors, with little shared variance. The semi-partial standardized coefficients are nearly identical to the standardized coefficients; their joint variance represents only $2.4 \%$ of the total variance explained $(37.5 \%)$ in the regression model presented in Table 5 (Abdi, 2007; Cohen \& Cohen, 1975).

First, consistent with previous findings (e. g., Ncube \& Moroke, 2015; O’Bryant, 2017), when students perceived their statistics classes as more valuable, interesting, achievable, enjoyable, and/or worthy of effort, they were also more likely to experience lower levels of statistics anxiety. Considering that attitudes are partly shaped before the first statistics class even begins, social sciences students may be particularly at risk of holding negative attitudes towards statistics if they had negative experiences with mathematics in the past. Nonetheless, attitudes can change as the course unfolds. Some of these attitudes can be influenced by the methods employed by the instructor when introducing the course content. For instance, hosting a discussion on the value of statistics, its utility, and difficulty may have a positive influence on attitudes. It may be worthwhile to stress the importance of statistics in the context of specific jobs. For example, many psychology students are interested in becoming clinicians. Not all of them, however, are aware of the value their statistical training will have in their future profession. This lack of recognition of the value of statistics in their career may result in poorer attitudes towards statistics and consequently, more statistics anxiety.

Second, when students live emotionally charged situations, they rely on regulation strategies, some more adaptive than others, to counter their stress reactions. The current study found that maladaptive strategies were associated with higher levels of statistics anxiety, whereas adaptive strategies may not be associated with levels of statistics anxiety (although if there is an effect it is in the expected direction). Maladaptive cognitive emotion regulation strategies include self-blame and rumination, among others. Interestingly, these suboptimal regulation strategies were also negatively related to the satisfaction of one's psychological needs $(r=-0.33)$, whereas adaptive cognitive emotion regulation strategies were positively related to the latter $(r=0.39)$. This suggests the possibility that helping students rid themselves of their maladaptive cognitive emotio0n regulation habits could benefit not only their anxiety in the context of a statistics course, but also their overall psychological well-being. Additionally, maladaptive cognitive emotion regulation strategies have direct repercussions on students' anxiety in their statistics course.

Noteworthy, our findings suggest a lack of relationship between maladaptive and adaptive cognitive emotion regulation strategies. Hence, choosing adaptive strategies does not prevent a student from using maladaptive strategies. Classroom interventions should aim at replacing maladaptive cognitive emotion regulation strategies with adaptive ones. 
Third, although there appeared to be no indirect moderation effect of satisfaction of psychological needs on statistics anxiety, our results indicate there may be a strong direct effect of satisfaction of psychological needs, whereby students whose psychological needs were not fulfilled were more likely to experience statistics anxiety. The amplitude of this relationship was at par with that of attitude towards statistics and statistics anxiety. According to Self-determination Theory, psychological needs take the form of feelings of autonomy regarding their choices, competence in their doings, and presence of meaningful relationships. Unsatisfied needs are thought to negatively impact a person's well-being, including their mental health (Ryan et al., 2008). Thus, it is possible that the distress resulting from unsatisfied psychological needs exacerbate the anxiogenic response to the statistics course. Nonetheless, in the context of this study, satisfied psychological needs, above other variables included in this study, can be interpreted as a protective factor with respect to statistics anxiety. Professors can be mindful of students' psychological needs for competence, autonomy, and relatedness when planning/teaching their course.

Lastly, the covariate of this study, gender, revealed that - consistent with existing literature (e.g., Cantinotti et al., 2017) - women were more likely than men to report statistics anxiety. This observation may be related to women being more likely to have greater negative attitudes towards statistics ( -7.4 points) and fewer adaptive regulation strategies (-6.1 points).

\subsection{IMPLICATIONS}

Results from the current study have numerous implications for the way we study and understand statistics anxiety in a population of undergraduate students in social sciences. To our knowledge, this study is the first of its kind to incorporate cognitive emotion regulation strategies and satisfaction of psychological needs in a model of statistics anxiety. Our results supplement previous research by showing that statistics anxiety can be predicted by both measures specifically designed to be used in a statistics context (attitudes towards statistics), and measures designed to assess everyday life concerns (cognitive emotion regulation strategies and satisfaction of psychological needs). Because the strength of the relationships between general measures and a specific anxiety may have been weakened by the difference in level of analysis, theory development should give careful consideration to the specificity of the measures. For example, feeling that one's psychological needs (autonomy, competence, and relatedness) are not satisfied within the statistics course context, compared to other course contexts, could explain the anxiogenic reaction to this subject. Conversely, the general level of satisfaction of those psychological needs might better predict one's general level of anxiety. Such investigation requires the development of specific measures for the statistical learning-environment. In the same vein, knowing that statistics is a source of anxiety among students, it would be worth identifying the exact coping strategies used by students to manage negative emotions triggered in the context of the statistics course. Are these strategies the same across all academic courses as they are outside of academic life? That said, person-specific factors may also provide useful information to understand this particular type of anxiety. Indeed, gender remained an important predictor of statistics anxiety, despite the inclusion of other variables to account for this effect, hence, suggesting that general factors, not specific to statistics, should be considered carefully. One example of a specific factor related to this population is the strong pressure and the fierce competition to enter graduate school experienced by psychology students wishing to become clinicians. Future studies should seek to measure how strongly the students experience this stressor.

\subsection{LIMITATIONS}

The present measures were taken at a single time during the semester (roughly past mid-semester). It is therefore not possible to see how statistics anxiety may evolve through the whole semester, and more relevant, how it evolves through the curriculum. Statistics classes are generally taken early in many psychology programs in which most of our participants were studying (first or second year). Yet, students are exposed to scientific reasoning and applications to psychological research generally in the late years of their program. Hence, there might be an attitude reappraisal following the presentation of positive use of 
statistics in their domain of study. This attitudinal change however occurs after the statistics class. It might therefore be informative to follow a cohort of students through the whole curriculum.

\section{CONCLUSIONS}

Overall, based on a sample of French-Canadian undergraduate students, this study corroborates previous findings that favorable attitudes towards statistics predict lower levels of statistics anxiety and that women experience more statistics anxiety than men. Moreover, we explored the influence of a concept specific to statistics (attitudes towards statistics), pitted against general measures applied to everyday life concerns (cognitive emotion regulation strategies and satisfaction of psychological needs). Results of this study suggest that statistic anxiety is well predicted by both statistics-specific concepts and situation-general factors with little overlap between the measures. More work on the relative importance of each factor will help us better understand statistics anxiety and means to reduce it. The current study suggests potential ways of reducing statistics anxiety of students studying in social sciences: discussing with the students i) what is the utility of statistics for their future career (increasing attitude); ii) how emotions can be maladaptively or adaptively regulated and how to avoid maladaptive regulation strategies, and iii) how the teaching activities should be approached as occasions to foster their feelings of autonomy, competence, and social support. All are easily achievable objectives. Whether these suggestions are effective manipulations remains to be demonstrated.

\section{ACKNOWLEDGEMENTS}

We would like to thank Rose-Marie Gibeau for her comments on an earlier version of this text. This research received institutional support from the Faculty of Social Sciences of the University of Ottawa awarded to Denis Cousineau.

\section{REFERENCES}

Abdi, H. (2007). Part (semi partial) and partial regression coefficients. In N. Salkind (Ed.). Encyclopedia of measurement and statistics (pp. 736-740). SAGE Publications.

Andrews, B., \& Wilding, J. M. (2004). The relation of depression and anxiety to life-stress and achievement in students. British Journal of Psychology, 95, 509-521. https://doi.org/10.1348/0007126042369802

Bartholomew, K. J., Ntoumanis, N., Ryan, R. M., Bosch, J. A., \& Thøgersen-Ntoumani, C. (2011). Selfdetermination theory and diminished functioning: The role of interpersonal control and psychological need thwarting. Personality and Social Psychology Bulletin, 37(11), 1459-1473. https://doi.org/10.1177/0146167211413125

Benson, J. (1987). Causal components of test anxiety in adults: An exploratory study. Annual Meeting of the Society for Test Anxiety Research, Austin, Texas.

Benson, J. (1989). Structural components of statistical test anxiety in adults: An exploratory model. Journal of Experimental Education, 57(3), 247-261. https://doi.org/10.1080/00220973.1989.10806509

Cantinotti, M., Lalande, D., Ferlatte, M. A., \& Cousineau, D. (2017). Validation de la version francophone du Questionnaire d'anxiété statistique (SAS-F-24). Canadian Journal of Behavioural Science, 49(2), 133-142. https://doi.org/10.1037/cbs0000074

Carillo, K., Galy, N., Guthrie, C., \& Vanhems, A. (2016). «J'aime pas les stats!» Mesure et analyse de l'attitude à l'égard du cours de statistique dans une école de management. Statistique et Enseignement, 7(1), 3-31. http://journal-sfds.math.cnrs.fr/index.php/StatEns/article/view/537

Chew, P. K. H., \& Dillon, D. B. (2014). Statistics anxiety update: Refining the construct and recommendations for a new research agenda. Perspectives on Psychological Science, 9(2), 196-208. https://doi.org/10.1177/1745691613518077 
Chiesi, F., \& Primi, C. (2009). Assessing statistics attitudes among college students: Psychometric properties of the Italian version of the Survey of Attitudes toward Statistics (SATS). Learning and Individual Differences, 19(2), 309-313. https://doi.org/10.1016/j.lindif.2008.10.008

Chiesi, F., \& Primi, C. (2010). Cognitive and non-cognitive factors related to students' statistics achievement. Statistics Education Research Journal, 9(1), 6-26. https://doi.org/10.52041/serj.v9i1.385

Cohen, J. \& Cohen, P. (1975). Applied multiple regression/correlation analysis for the behavioral sciences. Lawrence Erlbaum.

Cousineau, D. (2020). How many decimals? Rounding descriptive and inferential statistics based on measurement precision. Journal of Mathematical Psychology, 97, 102362. https://doi.org/10.1016/j.jmp.2020.102362

Cruise, R., Cash, R., \& Bolton, D. (1985). Development and validation of an instrument to measure statistical anxiety. American Statistical Association Proceedings of the Section on Statistical Education, 4(3), 92-97.

Deci, E., \& Ryan, R. (1980). Self-determination theory: When mind mediates behavior. Journal of Mind and Behavior, 1(1), 33-43.

Deci, E., \& Ryan, R. (1991). A motivational approach to self: Integration in personality. In R. A. Dienstbier (Ed.), Perspectives on Motivation, Nebraska Symposium on Motivation, Volume 38 (pp. 237-288). University of Nebraska Press.

Deci, E., \& Ryan, R. (1995). Human autonomy: The basis of true self-esteem. In M. H. Kernis (Ed.), Efficacy, agency, and self-esteem (pp. 31-49). Springer Science \& Business Media. https://doi.org/10.1007/978-1-4899-1280-0_3

Deci, E., \& Ryan, R. (2000a). Questionnaires: Basic psychological needs scales.

Deci, E., \& Ryan, R. (2000b). The "what" and "why" of goal pursuits: Human needs and the selfdetermination of behavior. Psychological Inquiry, 11(4), 227-268. https://doi.org/10.1207/S15327965PLI1104_01

Deci, E., Vallerand, R., Pelletier, L., \& Ryan, R. (1991). Motivation and education: The self-determination perspective. Educational Psychologist, 26(3-4), 325-346. https://doi.org/10.1080/00461520.1991.9653137

Dettmers, S., Trautwein, U., Lüdtke, O., Goetz, T., Frenzel, A. C., \& Pekrun, R. (2011). Students' emotions during homework in mathematics: Testing a theoretical model of antecedents and achievement outcomes. Contemporary Educational Psychology, 36(1), 25-35. https://doi.org/10.1016/j.cedpsych.2010.10.001

Evans, B. (2007). Student attitudes, conceptions, and achievement in introductory undergraduate college statistics. The Mathematics Educator, 17(2), 24-30.

Field, A. P. (2010). Non-sadistical methods for teaching statistics. In D. Upton \& A. Trapp (Eds.), Teaching Psychology in Higher Education (pp. 134-163). https://doi.org/doi:10.1002/9781444320732.ch6

Gal, I., \& Ginsburg, L. (1994). The role of beliefs and attitudes in learning statistics: Towards an assessment framework. Journal of Statistics Education, 2(2). https://doi.org/10.1080/10691898.1994.11910471

Garnefski, N., \& Kraaij, V. (2007). The cognitive emotion regulation questionnaire: Psychometric features and prospective relationships with depression and anxiety in adults. European Journal of Psychological Assessment, 23(3), 141-149. https://doi.org/10.1027/1015-5759.23.3.141

Garnefski, N., Kraaij, V., \& Spinhoven, P. (2001). Negative life events, cognitive emotion regulation and emotional problems. Personality and Individual Differences, 30(8), 1311-1327. https://doi.org/10.1016/S0191-8869(00)00113-6

Gross, J. J. (2001). Emotion regulation in adulthood: Timing is everything. Current Directions in Psychological Science, 10(6), 214-219. https://doi.org/10.1111/1467-8721.00152

Harding, B., Tremblay, C., \& Cousineau, D. (2014). Standard errors: A review and evaluation of standard error estimators using Monte Carlo simulations. The Quantitative Methods for Psychology, 10(2), 107123. https://doi.org/10.20982/tqmp.10.2.p107

Hodgins, H. S., Weibust, K. S., Weinstein, N., Shiffman, S., Miller, A., Coombs, G., \& Adair, K. C. (2010). The cost of self-protection: Threat response and performance as a function of autonomous and 
controlled motivations. Personality and Social Psychology Bulletin, 36(8), 1101-1114. https://doi.org/10.1177/0146167210375618

Hodgins, H. S., Yacko, H. A., \& Gottlieb, E. (2006). Autonomy and nondefensiveness. Motivation and Emotion, 30(4), 283-293. https://doi.org/10.1007/s11031-006-9036-7

Jermann, F., Van Der Linden, M., D’Acremont, M., \& Zermatten, A. (2006). Cognitive Emotion Regulation Questionnaire (CERQ): Confirmatory factor analysis and psychometric properties of the French translation. European Journal of Psychological Assessment, 22(2), 126-131. https://doi.org/10.1027/1015-5759.22.2.126

Kassel, J. D., Bornovalova, M., \& Mehta, N. (2007). Generalized expectancies for negative mood regulation predict change in anxiety and depression among college students. Behaviour Research and Therapy, 45(5), 939-950. https://doi.org/10.1016/j.brat.2006.07.014

Lalande, D., Cantinotti, M., Williot, A., Gagnon, J., \& Cousineau, D. (2019). Three pathways from achievement goals to academic performance in an undergraduate statistics course. Statistics Education Journal, 18(1), 94-105. https://doi.org/10.52041/serj.v18i1.152

Lalonde, R. N., \& Gardner, R. C. (1993). Statistics as a second language? A model for predicting performance in psychology students. Canadian Journal of Behavioural Science, 25(1), 108-125. https://doi.org/10.1037/h0078792

Lazar, A. (1990). Statistics course in social work education. Journal of Teaching in Social Work, 4(1), 1730. https://doi.org/10.1300/J067v04n01_03

Macher, D., Paechter, M., Papousek, I., \& Ruggeri, K. (2012). Statistics anxiety, trait anxiety, learning behavior, and academic performance. European Journal of Psychology of Education, 27(4), 483-498. https://doi.org/10.1007/s10212-011-0090-5

Macher, D., Paechter, M., Papousek, I., Ruggeri, K., Freudenthaler, H. H., \& Arendasy, M. (2013). Statistics anxiety, state anxiety during an examination, and academic achievement. British Journal of Educational Psychology, 83(4), 535-549. https://doi.org/10.1111/j.2044-8279.2012.02081.x

Macher, D., Papousek, I., Ruggeri, K., \& Paechter, M. (2015). Statistics anxiety and performance: Blessings in disguise. Frontiers in Psychology, 6, 4-7. https://doi.org/10.3389/fpsyg.2015.01116

Mills, J. D. (2004). Students' attitudes toward statistics: Implications for the future. College Student Journal, 38(3), 349.

Mji, A., \& Onwuegbuzie, A. J. (2004). Evidence of score reliability and validity of the statistical anxiety rating scale among technikon students in South Africa. Measurement and Evaluation in Counseling and Development, 36(4), 238-251. https://doi.org/10.1080/07481756.2004.11909745

Najmi, A., Raza, S. A., \& Qazi, W. (2018). Does statistics anxiety affect students' performance in higher education? The role of students' commitment, self-concept and adaptability. International Journal of Management in Education, 12(2), 95-113. https://doi.org/10.1504/IJMIE.2018.090705

Ncube, B., \& Moroke, N. D. (2015). Students' perceptions and attitudes towards statistics in South African university: An exploratory factor analysis approach. Journal of Governance and Regulation, 4(3), 231240. https://doi.org/10.22495/jgr_v4_i3_c2_p5

O'Bryant, M. J. (2017). How attitudes towards statistics courses and the field of statistics predicts statistics anxiety among undergraduate social science majors: A validation of the statistical anxiety scale [Doctoral thesis, University of North Texas]. https://eric.ed.gov/?id=ED584089

Olson, J. M., \& Zanna, M. P. (1993). Attitudes and attitude change. Annual Review of Psychology, 44(1), 117-154. https://doi.org/10.1146/annurev.ps.44.020193.001001

Omran, M. P. (2011). Relationships between cognitive emotion regulation strategies with depression and anxiety. Open Journal of Psychiatry, 1(03), 106-109. https://doi.org/10.4236/ojpsych.2011.13015

Onwuegbuzie, A. J. (2000). Attitudes toward statistics assessments. Assessment and Evaluation in Higher Education, 25(4), 321-339. https://doi.org/10.1080/713611437

Onwuegbuzie, A. J. (2003). Modeling statistics achievement among graduate students. Educational and Psychological Measurement, 63(6), 1020-1038. https://doi.org/10.1177/0013164402250989

Onwuegbuzie, A. J., Da Ros, D., \& Ryan, J. M. (1997). The components of statistics anxiety: A phenomenological study. Focus on Learning Problems in Mathematics, 19(4), 11-35. 
Papousek, I., Ruggeri, K., MacHer, D., Paechter, M., Heene, M., Weiss, E. M., Schulter, G., \& Freudenthaler, H. H. (2012). Psychometric evaluation and experimental validation of the statistics anxiety rating scale. Journal of Personality Assessment, 94(1), 82-91. https://doi.org/10.1080/00223891.2011.627959

Parker, S. L., Jimmieson, N. L., \& Amiot, C. E. (2013). Self-determination, control, and reactions to changes in workload: A work simulation. Journal of Occupational Health Psychology, 18(2), 173-190. https://doi.org/10.1037/a0031803

Quested, E., Bosch, J. A., Burns, V. E., Cumming, J., Ntoumanis, N., \& Duda, J. L. (2011). Basic psychological need satisfaction, stress-related appraisals, and dancers' cortisol and anxiety responses. Journal of Sport and Exercise Psychology, 33(6), 828-846. https://doi.org/10.1123/jsep.33.6.828

Rhoads, T. R., \& Hubele, N. F. (2000). Student attitudes toward statistics before and after a computerintegrated introductory statistics course. IEEE Transactions on Education, 43(2), 182-187. https://doi.org/10.1109/13.848071

Roberts, D. M., \& Bilderback, E. W. (1980). Reliability and validity of a statistics attitude survey. Educational and Psychological Measurement, 40(1), 235-238. https://doi.org/10.1177/001316448004000138

Roberts, D. M., \& Saxe, J. E. (1982). Validity of a statistics attitude survey: A follow-up study. Educational and Psychological Measurement, 42(3), 907-912. https://doi.org/10.1177/001316448204200326

Ryan, R. M., \& Deci, E. L. (2017). Self-determination theory: Basic psychological needs in motivation, development, and wellness. Guilford Press. https://psycnet.apa.org/doi/10.1521/978.14625/28806

Ryan, R. M., Patrick, H., Deci, E. L., \& Williams, G. C. (2008). Facilitating health behaviour change and its maintenance: Interventions based on self determination theory. The European Health Psychologist, $10(1), 2-6$.

Schau, C. (2003a). Students' attitudes: The "other" important outcome in statistics education. 2003 Joint Statistical Meetings - Section on Statistical Education, August (pp. 3673-3683). http://statlit.org/pdf/2003SchauASA.pdf

Schau, C. (2003b). Survey Attitudes Towards Statistics (SATS-36). https://www.evaluationandstatistics.com/

Schau, C., Stevens, J., Dauphinee, T., \& Vecchio, A. (1995). The development and validation of the Survey of Attitudes Toward Statistics. Educational and Psychological Measurement, 55(5), 868-875. https://doi.org/10.1177/0013164495055005022

Shankland, R. (2014). La psychologie positive. Dunod.

Slootmaeckers, K., Kerremans, B., \& Adriaensen, J. (2014). Too afraid to learn: Attitudes towards statistics as a barrier to learning statistics and to acquiring quantitative skills. Politics, 34(2), 191-200. https://doi.org/10.1111/1467-9256.12042

Thompson, R. A. (1991). Emotional regulation and emotional development. Educational Psychology Review, 3(4), 269-307. https://doi.org/10.1007/BF01319934

Vigil-Colet, A., Lorenzo-Seva, U., \& Condon, L. (2008). Development and validation of the Statistical Anxiety Scale. Psicothema, 20(1), 174-180. http://www.redalyc.org/articulo.oa?id=72720124

Watson, F. S., Kromrey, J. D., \& Hess, M. R. (2003). Toward a conceptual model for statistics anxiety intervention. Paper presented at the Annual Meeting of the Eastern Educational Research Association, February 27-March 1, Hilton Head, SC. http://eric.ed.gov/?id=ED477937

Watson, F. S., Lang, T. R., \& Kromrey, J. D. (2002). Breaking ground for EncStat: A statistics anxiety intervention program. 24. Paper presented at the Annual Meeting of the Florida Educational Research Association, November 6-8, Gainesville, FL. https://eric.ed.gov/?id=ed477936

Wei, M., Shaffer, P. A., Young, S. K., \& Zakalik, R. A. (2005). Adult attachment, shame, depression, and loneliness: The mediation role of basic psychological needs satisfaction. Journal of Counseling Psychology, 52(4), 591-601. https://doi.org/10.1037/0022-0167.52.4.591

Zeidner, M. (1991). Statistics and mathematics anxiety in social science students: Some interesting parallels. British Journal of Educational Psychology, 61(3), 319-328. https://doi.org/10.1111/j.20448279.1991.tb00989.x 
SARA-EMILIE McINTEE

136 Jean-Jacques Lussier Vanier Hall, School of Psychology, University of Ottawa Ottawa, Ontario, Canada K1N 6N5 